\title{
Trapped Penis and Urinary Retention in a Child with Severe Phimosis After Traditional Circumcision : A Case Report and Literature Review
}

\section{G. Botcho $^{1 *}$, Kar. Segbedji ${ }^{2}$, Tm. Kpatcha ${ }^{3}$, K. Tengue ${ }^{3}$, Ev. Sewa ${ }^{3}$, T. Dossouvi ${ }^{1}$, Leloua E, Ed. Dosseh ${ }^{4}$}

${ }^{1}$ Department of General Surgery of the University Teaching Hospital, Kara.

${ }^{2}$ Department of Pediatrics of the University Teaching Hospital, Kara.

${ }^{3}$ Department of Urology Andrology of the University Teaching Hospital of S.O, Lomé.

${ }^{4}$ Department of General Surgery of the University Teaching Hospital of S.O, Lomé.

*gabotcho@gmail.com; aristbo@yahoo.fr

*Corresponding Author: G. Botcho, Department of General Surgery of the University Teaching Hospital, Kara.

\section{Abstract}

Background: Phimosis is a common indication for circumcision. The finding of a trapped penis with significant penile abscess collection and urinary retention in a male infant following circumcision at home is indeed a rare occurrence.

Case History: A 18 months old male child was rushed to the Children's emergency unit with acute urinary retention, grossly swollen and trapped penis. There was a preceeding history of poor urinary stream five weeks following circumcision at home. Examination revealed a child in acute urinary retention with a grossly swollen, soft, fluctuant and tender mass concealing his penis. Abdomino pelvic Ultrasound scan revealed a distended urinary bladder with evidence of back pressure effects on both kidneys. He had immediate urinary diversion via a suprapubic puncture and subsequently in a few hours, had a re-do circumcision.

Conclusion: Male circumcision remains the surgical procedure which must be performed by practionner with expertise at hospital, in order to minimise the tragic complications.

Keywords: trapped penis ; urinary retention ; phimosis ; traditional circumcision ; Togo

\section{INTRODUCTION}

The circumcision is a surgical act which consist to ablate the foreskin in a way to let the glans penis overdrawn. It is mainly practice for a religious motive in our surroundings [1]. Considered wrongly as banal and humdrum geste, the circumcision lead to irreversible sequela when it is done in the poor condition with inappropriate tools and materials. Phimosis refers to clinical condition in which the foreskin cannot be retracted over the glans penis [2]. This could either be physiological or pathological. Pathological phimosis is characterized by scarring of the foreskin usually following surgery, trauma or inflammatory conditions like balaninitis xerotica obliterans [1]. It has been found to be a cause of obstructive uropathy and urinary retention in males [3]. A concealed penis on the other hand is one which may appear minute as a result of being buried in pre-pubic tissues, enclosed in scrotal tissue (penis palmatus), or trapped due to phimosis or a scar following circumcision or trauma [4]. A combination of severe phimosis associated with urinary retention and a trapped penis following a poorly performed circumcision is indeed uncommon. We present in this report a 18 months old boy with the above complaints managed in the department of the General Surgery at the University Teaching Hospital of Kara, Togo.

\section{CASE History}

A 18 months old boy was brought to the Children's Emergency Unit with a history of inability to pass urine and painful supra-pubic swelling. He also had a painful and grossly swollen penis associated with high 
grade fever. There was preceeding history of difficulty with passing urine as well as poor urinary stream of a month duration following circumcision at home 05 weeks prior. The circumcision was performed by a traditional healer. There was no history of trauma or foreign body insertion into the penis.

On examination, we found a male infant in painful distress, not pale but febrile. He had a distended and tender bladder. He also had a grossly swollen, soft, tender and fluctuant mass concealing the penis within the pre-pubic tissue and scrotum (penis palmatus). The external urethral meatus was occluded by tight phimosis and digital pressure yielded trickles of urine effluent (figure 1).

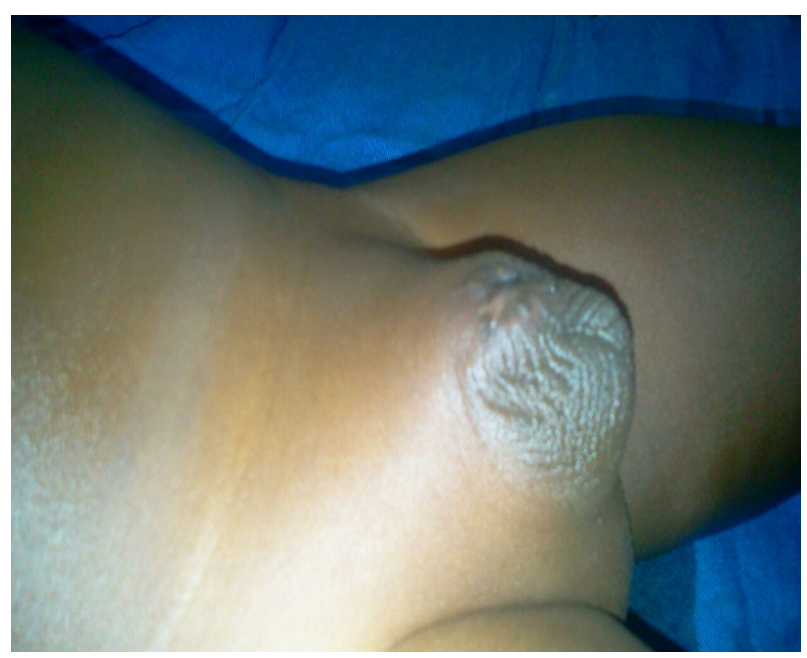

Figure 1. Phimosis with trapped penis

Complete blood count and renal function test were normal. The abdominopelvic ultrasound scan was in keeping with an acute on chronic urinary retention and mild bilateral hydro-ureteronephrosis. A diagnosis of Urinary retention secondary to severe phimosis with penile abscess collection was made.

He had an emergency suprapubic puncture, done to decompress the upper urinary tract and relieve the retention. He was also commenced on a 72 hours course of parenteral antibiotics.

He subsequently in a fewhours had a re-do circumcision carefully preserving normal skin, using the dorsal and ventral slit technique. We accessed to penis via a combination of dorsal and ventral slit. A ventral slit completed, the glans is visualized. Intra-operatively, about twenty (20) millilitres of infected purulent urine was found beneath the redundant foreskin and intense scar tissue adhering the foreskin with the glans penis. We have begun dissection to deglove penis by incision marked just below coronal marginal. Scarred penile skin was excised and remnant sutured to the corona. Immediate postoperative condition was satisfactory with a normal voiding and an acceptable cosmetic result (Figure 2).

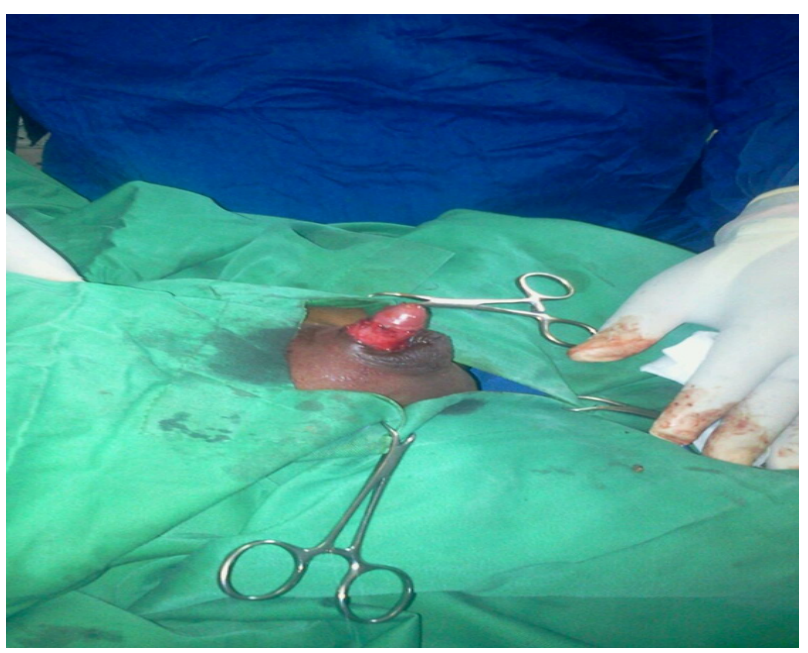

Figure 2. Immediately following re-do circumcision

\section{Discussion}

The circumcision is the excision of foreskin in totality. It is the most practiced surgical procedure in male. It is also the most practiced by paramedic personnel or by traditional healer because of the benignity of this practice in Togo [1]. This usually leads to complications such as amputated glans penis, stenosis of urethral meatus, urethral fistula, necrosis of the foreskin, penile gangrene, trapped penis, curvature and deviation of the penis. Kimassoum et al [5] in N'Djamena (Tchad) found in their study that the circumcision could be fraught by various range of complications when executed by untrained personnel. Osifo et al. [6] in a retrospective review of 346 boys who presented with circumcision related complications in a tertiary hospital in Southern Nigeria found that untrained personnel executed majority of circumcisions. The rate of traditional circumcision is still high in West Africa because of the lack of sanitary coverage and some religious custom and believing [7].

Phimosis is a rare complication following circumcision. It is the commonest medical indication for circumcision. Few reports have shown significant urinary retention and upper tract affection secondary 
Trapped Penis and Urinary Retention in a Child with Severe Phimosis After Traditional Circumcision : A Case Report and Literature Review

to severe phimosis, however these were found in teenagers and not in infant as in this report [3]. This further confirms the severity of this post-circumcision phimosis. The urinary retention necessitated an emergency suprapubic puncture and subsequent redo circumcision in our case contrariwise Igbokwe et al. [8] had made firstly suprapubic cystostomy in emergency before re-do circumcision.

The trapped penis in our case was due to a retractile scar tissue following the circumcision and was a result of significant collection of infected urine within the foreskin as a result of the phimotic obstruction. Differential diagnosis of an amputated glans penis was actually being entertained prior to surgery, this is a known complication of circumcision [6].

Surgery is the treatment of choice for pathological phimosis [9]. In our case, we used the dorsal and ventral slit technique contrariwise Igbokwe et al. [8] used only dorsal slit technique. There is several surgical techniques for this pathology [4, 10 - 12].

\section{CONCLUSION}

Male circumcision remains the surgical procedure which must be performed by practionner with expertise at hospital, in order to minimise the tragic complications. Pathologicalphimosis, urinaryretention and trapped penis are possible consequences from traditional circumcision. A high index of suspicion, prompt urinary diversion and re-do circumcision are critical to ensure a healthy child.

\section{REFERENCES}

[1] Gnassingbé K, Akakpo-Numado KG, Anoukoum T, Kanassoua K, Kokoroko E, Tékou H. La circoncision: pourquoi et comment est-elle pratiquée chez le nouveau-né et le nourrisson au CHU de Lomé ? Prog Urol. 2009; 19 : 572-5.

[2] Chan IH, Wong KK. Common urological problems in children: prepuce, phimosis, and buried penis. Hong Kong medical journal $=$.Xianggang yi xue za zhi / Hong Kong Academy of Medicine. 2016; 22 (3): 263-9.

[3] Tomita K, Kakizawa Y, Yoshida M. A case of true phimosis with bilateral hydroureteronephrosis and bilateral vesicoureteral reflux. Hinyokika kiyo Acta urologica Japonica. 1991; 37 (3): 283-5.

[4] Radhakrishnan J, Razzaq A, Manickam K. Concealed penis. Pediatric surgery international. 2002; 18(8) : 668-72.

[5] Spilsbury K, Semmens JB, Wisniewski ZS, Holman CD. Circumcision for phimosis and other medical indications in Western Australian boys. The Medical journal of Australia. 2003; 178 (4): 155-8.

[6] Osifo OD, Oriaifo IA. Circumcision mishaps in Nigerian children. Annals of African medicine. 2009; 8 (4): 266-70.

[7] Kimassoum R, Franklin DS, Arya ZAT, Mignagnal K. Epidemiological, clinicopathological and therapeutic features of circumcision complications. Uro'Andro. 2016 ; 1 (5) : 218 - 224.

[8] Igbokwe MC, Faye ST, Ndoye M, Jalloh M, Mbodj $M$, Niang $L$ et al. Concealed penis and urinary retention in a child with severe phimosis : a case report. Uro'Andro. 2016; 1 (6) : 261 - 3.

[9] Shahid SK. Phimosis in children. ISRN Urology. 2012; 2012: 707329.

[10] Radhakrishnan J, Reyes HM. Penoplasty for buried penis secondary to «radical» circumcision. Journal of Pediatric Surgery. 1984 ; 19 (6) : 629-31.

[11] Borsellino A, Spagnoli A, Vallasciani S, Martini L, Ferro F. Surgical approach to concealed penis: technical refinements and outcome. Urology. 2007; 69 (6) : 1195-8.

[12] Kim JJ, Lee DG, Park KH, Baek M. A novel technique of concealed penis repair. Eur J. Pediatr Surg. 2014 ; 24 (2) : 158-62.

Citation: G. Botcho, Kar. Segbedji, Tm. Kpatcha, et al. Trapped Penis and Urinary Retention in a Child with Severe Phimosis After Traditional Circumcision : A Case Report and Literature Review. Archives of Urology. 2018; 1(2): 26-28.

Copyright: (c) 2018 G. Botcho, Kar. Segbedji, Tm. Kpatcha, et al. This is an open access article distributed under the Creative Commons Attribution License, which permits unrestricted use, distribution, and reproduction in any medium, provided the original work is properly cited. 